Saudi Journal of Medicine

Abbreviated Key Title: Saudi J Med ISSN 2518-3389 (Print) |ISSN 2518-3397 (Online) Scholars Middle East Publishers, Dubai, United Arab Emirates Journal homepage: http://scholarsmepub.com/sjm/

Original Research Article

\title{
Ankylosing Spondylitis among Patients Attending the Rheumatology Outpatient Department of a Specialist Hospital
}

\author{
Dr. Akintayo Segun Oguntona. MBChB, FWACP ${ }^{1 *}$, Dr. Ricardo Morasen Cuevas Jose² ${ }^{2}$, Dr. Mazwa Hussein ${ }^{2}$ \\ ${ }^{1}$ Consultant Rheumatologist- Olabisi Onabanjo University Teaching Hospital, Sagamu, Nigeria \\ ${ }^{2}$ Specialist in Rheumatology- King Abdul-Azeez Specialist Hospital, Sakaka, Saudi Arabia
}

\begin{abstract}
DOI: $10.36348 / \mathrm{sjm} .2020 . v 05 i 01.005$
| Received: 08.01.2020 | Accepted: 15.01.2020 | Published: 19.01.2020
\end{abstract}

*Corresponding author: Akintayo Segun Oguntona

Abstract

Background: Ankylosing spondylitis (AS) belongs to a group of related disorders called spondyloarthropathies. It is the most common and most typical form of spondyloarthropathy. Men are usually affected three times more than women. The disease is characterized with inflammatory back pain starting in adolescence and early adulthood. When patients are diagnosed after the age of 45 years, it is possibly because symptoms over the years have been minimal. Methods: This was a prospective study of patients that were seen in the rheumatology out-patients department of a specialist hospital over a period of one year. A detailed history of back pain, heel pain, enthesopathy and peripheral arthritis were obtained. Histories of conjunctivitis, urethritis, inflammatory bowel disease and family history of ankylosing spondylitis were obtained. Inclusion criteria were patients that were previously diagnosed as AS and those who met the modified New York criteria for classification of AS. A thorough examination of spinal and extra-spinal regions was carried out. Investigations carried out included rheumatoid factor, tissue typing, plain radiograph and magnetic resonance image of the sacroiliac joints. Results: There were 840 patients that presented in the rheumatology clinic over the study period. Thirty two patients presented with various spondyloarthropathies while 12 of them were diagnosed as ankylosing spondylitis. Male to female ratio was 11: 1 . The age range of the patients was $18-54$ years with a mean of $46 \pm 4$ years. The duration of symptoms varied between 9 months to 28 years. Frequencies of initial presentation were low back pain in five, peripheral arthritis in four, heel pain in two and uveitis in one patient. Extra-articular presentations included aortic incompetence, pulmonary fibrosis and non-specific abdominal pain. All the patients had sacroiliitis. Joint involvement was asymmetrical and joints of the lower limbs were majorly affected. Test for rheumatoid factor was negative in all the patients while 6 patients had HLA-B27 antigen positive. Etanercept was the frequently used medication. Conclusion: AS was predominantly diagnosed in male patients. Spinal arthritis, peripheral arthritis and extra-articular manifestations among the Arabs were as documented among the whites. Response to etanercept was uniformly good.

Keywords: Spondyloarthropathy, Ankylosing spondylitis, Rheumatology.

Copyright @ 2020: This is an open-access article distributed under the terms of the Creative Commons Attribution license which permits unrestricted use, distribution, and reproduction in any medium for non-commercial use (NonCommercial, or CC-BY-NC) provided the original author and source are credited.

\section{INTRODUCTION}

Ankylosing spondylitis (AS) is a chronic inflammatory disease. It has an insidious onset and characterized by low back and buttock pain with associated morning stiffness [1]. The onset is usually during adolescence or early adulthood1. Sacroiliitis with syndesmophyte formation, which is seen in advanced disease, can lead to spinal ankylosis or formation of so-called bamboo spine [2].

The pathogenesis of AS is poorly understood. However, major histocompatibility complex (HLAB27), inflammatory cellular infiltrates and cytokines are implicated [3]. The prevalence of AS in different cohorts frequently relates to the prevalence of this major histocompatibility complex (MHC) molecule in the study population [3]. Ethnic, racial and geographical factors are associated with the occurrence and expression of the disease. The role of environmental factor is however not well understood. Populationbased studies have previously reported considerable variability in the prevalence of AS, ranging from 0.1 $1.4 \%$ and up to $6 \%[4]$.

Arthritis of peripheral joints, costochondritis and enthesopathy are also commonly observed [5]. Extra-articular manifestations of AS include iritis and prostatitis. Asymptomatic gastrointestinal tract involvement has also been described. Cardiac and pulmonary involvements are not very common [6]. 
The diagnostic criteria most often used are the modified New York criteria published in 1984[7]. These criteria involve both clinical and radiological aspects. The clinical diagnosis is supported by radiologic evidence of sacroiliitis, which is still considered to be the radiographic hallmark of ankylosing spondylitis [8]. Magnetic resonance imaging (MRI) is the radiograph of choice in early disease or when standard radiograph shows equivocal changes [9]. Magnetic resonance imaging, especially with gadolinium enhancement, produces excellent evidence of sacroiliitis and enthesitis[9].

Patients with ankylosing spondylitis that is unresponsive to conventional therapies with nonsteroidal anti-inflammatory drugs usually respond well to anti-tumor necrosis factors [10]. Treatment with these agents rapidly improved peripheral arthritis, enthesitis, and axial signs and symptoms [10].

\section{MATERIALS AND METHODS}

The patients were seen in the rheumatology out-patient department of a specialist hospital over a period of one year. Each patient was questioned in detail about history of back pain, peripheral joint symptoms, heel pain, symptoms of acute anterior uveitis conjunctivitis, urethritis, inflammatory bowel disease, and mucosal and skin lesions. Past and family histories of these disorders were also recorded.

A thorough physical examination was done with special attention to the spine, peripheral joints, eyes, skin, buccal mucosa, genitalia, chest, and cardiovascular systems. The chest expansion value was set at $\geq 6 \mathrm{~cm}$ for males and $\geq 4.5 \mathrm{~cm}$ for female. Lumbar flexibility was evaluated by the Schober's test and measured in centimetres $(\mathrm{cm})$. Cervical flexion, extension and rotation were evaluated according to standard clinical measurements. The extent of extraspinal symptoms was also assessed according to standard clinical evaluation. Patients that presented with iritis were reviewed by the Ophthalmologist.

Tissue typing was done and test for rheumatoid factor by the standard latex agglutination test was requested. Posterio-anterior and oblique view radiographs of the sacroiliac joints were done. MRI was done in all the patients. All radiographs and magnetic resonance imaging were read by the Radiologists and re-evaluated by members of the study group.

\section{Inclusion criteria}

The modified New York criteria [7] for classification of AS (12), was use for the purpose of this study. It requires that patients must have a radiological criterion of sacroiliitis grade 2 bilaterally or grade 3 or 4 unilaterally and at least one of the three following clinical signs:
- Low back pain and stiffness for more than three months that improve with exercise but are not relieved by rest.

- Limitation of motion of the lumbar spine in both the sagittal and the frontal planes.

- Limitation of chest expansion relative to normal values correlated for age and sex.

Patients that were previously diagnosed as AS (Ankylosing spondylitis) by a rheumatologist and on medications were also included. Patients with another rheumatic disease other than AS were excluded from the study.

\section{RESULTS}

A total of 840 patients were seen in the rheumatology out-patient department from July 2018 to June 2019. There were 32 patients that presented with various spondyloarthropathies while 12 of them were diagnosed as ankylosing spondylitis - 11 men and a woman $(\mathrm{M}: \mathrm{F}=11.1)$. The age range of our patients was 18 - 54 years with a mean of $46 \pm 4$ years. The mean age at diagnosis of AS was $26 \pm 3$ years while 3 of them developed the disease before the age of 20 years.

The duration of symptoms varied from 9 months to 28 years. The initial symptoms recorded among the patients are as follows; low back pain in 5 $(41.7 \%)$, peripheral arthritis in $4(33.3 \%)$, heal pain in 2 $(16.7 \%)$ and uveitis in $1(8.3 \%)$. Extra-articular presentations observed included uveitis $3(25 \%)$, aortic incompetence $2(16.7 \%)$, apical pulmonary fibrosis 1 $(8.3 \%)$ and non-specific abdominal pain 1 (8.3\%). Those with only spinal disease $(2=16.7 \%)$ had a lower onset of duration of disease (less than 5 years) than those with extra-articular features.

The joints of the lower limbs were mainly affected in ten $(83.3 \%)$ patients. Four $(33.3 \%)$ patients had arthritis at the beginning of the illness while the remaining six $(50 \%)$ patients developed arthritis during the course of the disease. Joint involvement was asymmetrical and a range of 1 to 3 joints were affected.

Achilles tendonitis was observed in three $(25 \%)$ patients while plantar fasciitis was seen in 4 $(33.3 \%)$ patients. According to the x-ray definition of saciliitis by the New York criteria, all the patients had bilateral sacroiliitis. Seven $(58.3 \%)$ patients had grade II sacroiliitis and five $(41.7 \%)$ had grade III $\mathrm{x}$-ray changes in the sacroiliiac joints. The severity of these changes correlated well with the duration of disease.

Test for rheumatoid factor was negative in sera of all the patients. HLA-B27 antigen was detected in 6 males while the only female was negative. Thus the prevalence of HLA-B27 positive individuals was $50 \%$. 
All the patients were placed on etanercept. One patient however developed an intolerable adverse effect of vomiting to etanercept and was changed to humira. Non-steroidal anti-inflammatory drug (NSAID) was prescribed as necessary.

Table-1: Characteristics of ankylosing spondylitis patients seen during the study period

\begin{tabular}{|l|l|}
\hline Characteristic & Result \\
\hline Total number of patients & 12 \\
\hline Male to Female & 11 to 1 (11:1) \\
\hline Age range & 18 - 54 years \\
\hline Mean age & $46 \pm 4$ years \\
\hline Mean age at disease onset & $26 \pm 3$ years \\
\hline Duration of symptoms & 9 months to 28 years \\
\hline HLA B27 positivity & $6(50 \%)$ \\
\hline Number with Axial involvement & $9(75 \%)$ \\
\hline Number with peripheral joint involvement & $10(83.3 \%)$ \\
\hline Range of peripheral joint & $1-3$ \\
\hline Extra-articular involvement & \\
Uveitis & $3(25 \%)$ \\
Aortic insufficiency & $2(16,7 \%)$ \\
Apical pulmonary fibrosis & $1(8.3 \%)$ \\
Non-specific abdominal pain & $1(8.3 \%)$ \\
Achilles tendinitis & 3 \\
Plantar fasciitis & 4 \\
\hline Sacroiliitis & $7(58.3 \%)$ \\
Grade 2 & $5(41.7 \%)$ \\
Grade 3 & \\
\hline
\end{tabular}

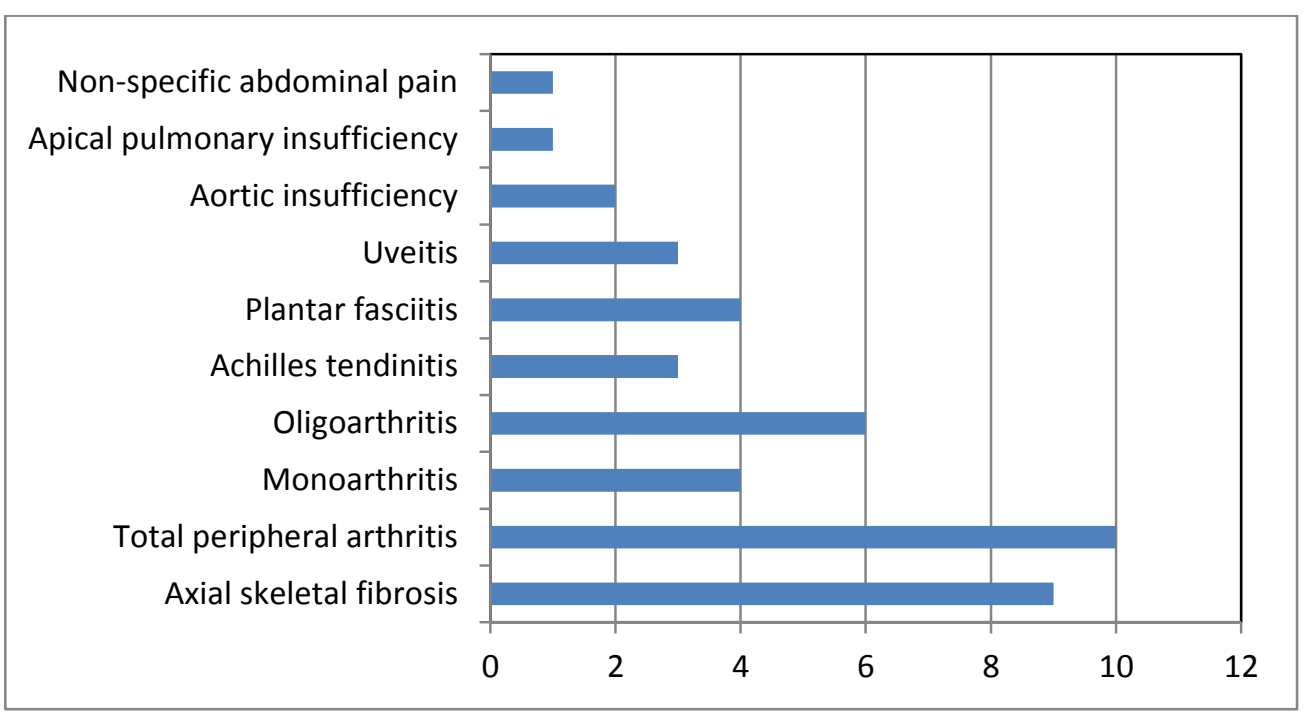

Fig-1: Clinical presentations among ankylosing spondylitis patients seen during the study period

\section{DISCUSSION}

There exist significant geographical variations in the occurrence of AS in different areas of the world [11]. Genetic, ethnic, racial and environmental factors are likely to influence the occurrence and clinical expression of AS [4].

The disease is less common among black Americans than in whites, and seems to be extremely rare among black African populations [12]. Ankylosing spondylitis is considered to be closely associated with the HLA-B27 molecule [3].
The findings of the present study indicate that the clinical and the HLA profile of ankylosing spondylitis among Saudi is generally similar to that reported from the western Countries. The sex ratio of this study was 11.1 (M:F). Population based studies have shown a significant variation in sex ratio ${ }^{4}$. A ratio of 5.4:1 was found among the Japanese and 2.3:1 in the Finnish study. Patient based studies have also shown a male predominance, with sex ratios varying widely among racial and ethnic groups [13].

It has been postulated that a lower occurrence of AS among females could be that females may require 
a higher genetic susceptibility load before they present with the disease [14]. Studies have also found that the disease is diagnosed less frequently in women, because axial symptoms are less severe, however, Peripheral arthritis is likely to be more prominent in women [15].

The mean age at diagnosis of AS among our patients was $26 \pm 3$ years. It is a disease with onset of duration of $18-40$ years. It is difficult to compare the mean duration of onset of disease between men and women because only one woman was affected in this study. There were variations in the finding of different studies as regards the mean age at diagnosis between males and females. The mean age at diagnosis was higher in men than in women in the study by Prakash et al. [16]. Rochester [17] and Finland [18] found no difference in the mean age between men and women while the Japanese study found the mean age at diagnosis to be significantly higher among women [19].

As with other studies, peripheral joints involvement characteristically mono- or oligoarthritis of the lower limbs, the Achilles tendon, uveal tract, and cardiovascular systems were also affected. A notable difference of this study however from the earlier studies was the onset of peripheral arthritis almost as frequent as with low back symptoms. The explanation for this could be the diagnosis of AS in three individuals below 20 years of age in whom the disease usually starts in the peripheral joints.

The earlier onset of AS among these adolescents may be because of their exposure to the implicated environmental agents at a younger age. The chances of infections early in life with the enteric microbes like Klebsiella which are implicated in the causation of AS is a possibility among these adolescents [20]. The other possible explanation for almost equal onset of both peripheral and back pain in this study is the possibility that the patients may have started as Reiter's disease but might have forgotten the mild urethritis or conjunctivitis associated with the arthritis.

Extra-articular features present among our patients included Uveitis, aortic inssufiency, apical pulmonary fibrosis and non-specific abdominal pain. Extra-articular features of ankylosing spondylitis can involve almost any organ system [21]. Anterior uveitis is the most frequent extra-articular manifestation, occurring in 25 to 30 percent of patients [21]. The uveitis usually is acute, unilateral, and recurrent. Eye pain, red eye, blurry vision, photophobia, and increased lacrimation are presenting signs. Cardiac manifestations may include aortic and mitral root dilatation, with regurgitation and conduction defects [22]. Fibrosis may develop in the upper lobes of the lungs in patients with long standing disease [22].
Fifty percent of the patients in the study were positive for HLA B27. The prevalence of HLA-B27 in various populations has been found to correlate to some extent with the population prevalence of AS in the same cohort [23]. This thus suggests that HLA-B27 mediates important antigen presentation which has a role in the pathogenesis of AS.

Among the Caucasians in Western Europe, $90 \%$ with AS are HLA-B27 positive, as compared with around $8 \%$ in the general population [24]. Varied prevalence of HLA-B27 in different populations, may likely reflect the importance of other pathogenetic factors, including various environmental factors in the pathogenesis of AS. HLA-B27 positive patients seem to experience disease symptoms at a younger age and they also more frequently have iritis and arthritis in peripheral joints [25]. This finding corroborated the finding in this study where the three patients with AS below age of 20 years had peripheral arthritis.

In conclusion, the onset of symptoms was generally earlier in those with only spinal disease than those who presented with extra-articular symptoms. There was a linear correlation between the duration of symptoms and severity of radiological findings. HLAB27 positivity seems to correlate with severe disease with extra-articular manifestations.

\section{REFERENCES}

1. Gran, J.T., Husby, G. (1993). The epidemiology of ankylosing spondylitis. Semin Arthritis Rheum, 22: 319-334.

2. Khan, M.A. (2003). Clinical features of ankylosing spondylitis. In: Hochberg M, Silman A, Smolen J, Weinbatt M (Eds.) Rheumatology. London: Mosby: A Division of Harcourt Health Sciences Ltd. 1161-1181.

3. Smith, J.A., Marker-Hermann, E., Colbert, R.A. (2006). Pathogenesis of ankylosing spondylitis: current concepts. Best Pract Res Clin Rheumatol, 20: 571-591.

4. Kaipiainen-Seppanen, O., Aho, K., Heliovaara, M. (1997). Incidence and prevalence of ankylosing spondylitis in Finland. J Rheumatol, 24: 496-499.

5. Singh, G., Lawrence, A., Agarwal, V., Misra, R., Aggarwal, A. (2008). Higher prevalence of extraarticular manifestations in ankylosing spondylitis with peripheral arthritis. J Clin Rheumatol, 14: 264-266.

6. Lau, C.S., Burgos-Vargas, R., Louthrenoo, W., Mok, M.Y., Wordsworth, P., Zeng, Q.Y. (1998). Features of spondyloarthropathies around the world. Rheum Dis Clin North Am. 24:753-770.

7. Van Der Linden, S., Valkenburg, H.A., Cats, A. (1984). Evaluation of diagnostic criteria for ankylosing spondylitis: A proposal for modification of the New York criteria. Arthritis Rheum, 27: 361-368. 
8. Stafford, L., Youssef, P.P. (2002). Spondyloarthropathies: an overview. Intern Med J. 32:40-46.

9. Bredella, M.A., Steinbach, L.S., Morgan, S., Ward, M., Davis, J.C. (2006). MRI of the sacroiliac joints in patients with moderate to severe AS. Am J Roentgenol. 187: 1420-1426.

10. Gorman, J.D., Sack, K.E., Davis, J.C Jr. (2002). Treatment of ankylosing spondylitis by inhibition of tumor necrosis factor alpha. $N$ Engl J Med. 346:1349-1356.

11. Van der Linden, S., van der Heijde, D. (2001). Ankylosing spondylitis. In: Ruddy S, Harris ED Jr, Sledge CB, eds. Kelley's Textbook of rheumatology. 6th ed. Philadelphia: Saunders, 1039-1054.

12. Mijiyawa, M., Oniankitan, O., Khan, M.A. (2001). Spondyloarthropathies in sub-Saharan Africa. Curr Opin Rheumatol, 12:281-286.

13. Sieper, J., Braun, J., Rudwaleit, M., Boonen, A., Zink, A. (2002). Ankylosing spondylitis: an overview. Ann Rheum Dis. 61(suppl 3) 8-18.

14. Miceli-Richard, C., Said-Nahal, R., Breban, M. (2000). Impact of sex on inheritance of ankylosing spondylitis. Lancet, 355: 1097-1098.

15. Lee, W., Reveille, J.D., Davis, J.C. Jr., Learch, T.J., Ward, M.M., Weisman, M.H. (2007). Are there gender differences in severity of ankylosing spondylitis? Results from the PSOAS cohort. Ann Rheum Dis, 66: 633-638.

16. Sanjeev, P., Narinder, K.M., Sneh, B., Mahesh, C.V., Anand, N.M. (1984). Ankylosing spondylitis in North India: a clinical and immunogenetic study. Annals of the Rheumatic Diseases, 43, 381-385.

17. Carbone, L.D., Cooper, C., Michet, C.J., Atkinson, E.J., O’Fallon, W.M., Melton, L.J. 3rd. (1992).
Ankylosing spondylitis in Rochester, Minnesota, 1935-1989: Is the epidemiology changing? Arthritis Rheum, 35: 1476-1482.

18. Kaipiainen-Seppanen, O., Aho, K., Heliovaara, M. (1997). Incidence and prevalence of ankylosing spondylitis in Finland. J Rheumatol, 24(3):496499.

19. Nakashima, Y., Ohishi, M., Okazaki, K., Fukushi, J., Oyamada, A., Hara, D. (2016). Delayed diagnosis of ankylosing spondylitis in a Japanese population. Mod Rheumatol, 26(3):421-425.

20. Van Praet, L., Van den Bosch, F.E., Jacques, P., Carron, P., Jans, L., Colman, R. (2013). Microscopic gut inflammation in axial spondyloarthritis: A multiparametric predictive model. Ann Rheum Dis, 72:414-417.

21. Monnet, D., Breban, M., Hudry, C., Dougados, M., Brezin, A.P. (2004). Ophthalmic findings and frequency of extraocular manifestations in patients with HLA-B27 uveitis: a study of 175 cases. Ophthalmology, 111:802-809.

22. Braun, J., Sieper, J. (2007). Ankylosing spondylitis. Lancet, 369:1379-1390.

23. Reveille, J.D., Hirsch, R., Dillon, C.F., Carroll, M.D., Weisman, M.H. (2012). The prevalence of HLA-B27 in the US: data from the US National Health and Nutrition Examination Survey, 2009. Arthritis Rheum, 64: 1407-1411.

24. Brown, M.A. (2010). Genetics of ankylosing spondylitis. Curr. Opin. Rheumatol, 22: 126-132.

25. Reed, M.D., Dharmage, S., Boers, A., Martin, B.J., Buchanan, R.R., Schachna, L. (2008). Ankylosing spondylitis: an Australian experience. Intern Med J. 38:321-327. 